\title{
Do rats prefer information about shock intensity?
}

\author{
JAMES FREEMAN and PIETRO BADIA \\ Bowling Green State University, Bowling Green, Ohio 43403
}

\begin{abstract}
The question asked in the present research was whether rats prefer information about the intensity of shock to be delivered. Seven albino rats were given random (variable interval 60 sec) shocks of two different intensities (either .5 mA and $1.0 \mathrm{~mA}$ or $0 \mathrm{~mA}$ and $1.0 \mathrm{~mA}$ ). By pressing a lever, subjects could, under one condition, produce, or under a second condition, eliminate stimuli correlated with the two shock intensities for 1-min periods. None of the subjects demonstrated any appreciable preference for either condition. For these subjects later given the option of changing from an unsignaled to a signaled shock condition, all changed over to the signaled condition. These results were discussed in terms of predictions derived from the preparation, information, and safety hypotheses.
\end{abstract}

Considerable attention has been devoted to the importance of information in controlling choice behavior. In the appetitive situation, it has been shown that information about the presence and absence of a reward and the quantity and quality of a reward (Levis \& Perkins, 1965; Mitchell, Perkins, and Perkins, 1965; McLaughlin, Note 1) affects choice performance. In the aversive situation, most of the research on choice performance has dealt with information pertaining to the presence and absence of the aversive event (e.g., Badia \& Culbertson, 1972; Badia, Culbertson, \& Lewis, 1971; Lockard, 1963). There are apparently no data available dealing with how information about the quality or quantity of the aversive event affects choice behavior. The intensity of the noxious stimulation would seem to be particularly relevant. Is information about the intensity of noxious stimulation important, given that the subjects already know when it is due? For instance, in a signaled unavoidable and inescapable shock situation, where shocks of two different intensities are delivered on a random schedule, do subjects prefer to have information about the intensity of the shock that is to be delivered? The present research deals specifically with this problem.

\section{METHOD}

\section{Subjects}

Seven naive adult female albino rats were obtained from the Holtzman Company (Madison, Wisconsin). All subjects were between 120-150 days old at the start of the experiment and housed in individual cages where food and water were available on a free feed basis.

\section{Apparatus}

Subjects were tested in a two-lever Foringer operant conditioning chamber, modified so that the grid bars were perpendicular to the levers. The chamber was $36.8 \mathrm{~cm}$ long, $25.4 \mathrm{~cm}$ wide, and $12.7 \mathrm{~cm}$ high $(14 \times 10 \times 5 \mathrm{in}$.$) . The levers$

This research was supported in part by Grant GB-33725 from the National Science Foundation and by funds made available from the Faculty Research Committee of Bowling Green State University. Reprints may be requested from Pietro Badia, Department of Psychology, Bowling Green State University, Bowling Green, Ohio 43403 . required a force of $20 \mathrm{~g}$ to depress and were $5 \mathrm{~cm}(2 \mathrm{in.})$ from the side along the $25.4-\mathrm{cm}$ (10 in.) wall, $7.65 \mathrm{~cm}$ ( $3 \mathrm{in}$.) above the grid floor. Both levers were effective for changeover responding. A $5-\mathrm{sec} 1,000-\mathrm{Hz}$ tone $(84 \mathrm{~dB})$ served as the preshock warning stimulus and was delivered through a speaker mounted behind the stimulus panel. The floor consisted of a series of $.64 \mathrm{~cm}(.25 \mathrm{in}$.$) in diam, spaced 1.3 \mathrm{~cm}(.5 \mathrm{in}$.$) apart,$ center to center. Grids were positioned perpendicular to the wall containing the levers. A Lehigh Valley constant current shock source delivered shock. The walls and response levers served as one contact in the grid scrambling circuit. Background noise level in the chamber produced by ventilating fans was 77-79 dB as measured on the $C$ scale of a General Radio Corporation sound meter. Programming was accomplished with electromechanical equipment, and data were recorded on counters, clocks, and event recorders.

\section{Procedure}

Subjects were run in sessions lasting $6 \mathrm{~h}$ every other day. Shocks were delivered on a variable interval (VI) schedule with a mean of $60 \mathrm{sec}$ and a range from 8-612 sec. All VI schedules were generated from Fleshler and Hoffman (1962) tables using 20 intervals. The onset of a $24-\mathrm{V}$ dc bulb $(590 \mathrm{k})$, capped by a $2.54-\mathrm{cm}(1 \mathrm{in}$.) white jeweled lens and located above the right lever, served as the stimulus correlated with periods of high intensity shock (1.0 mA) for Subjects A4, A5, A6, A7, A8. For these subjects, the same light when flashing at the rate of $1 \mathrm{sec}$ on and $1 \mathrm{sec}$ off served as the stimulus correlated with periods of low-intensity shock $(.5 \mathrm{~mA})$ or no shock. For Subjects A3 and A9, the constant light was correlated with periods of low-intensity shock $(.5 \mathrm{~mA})$ or no shock, and the flashing light was correlated with high-intensity shock $(1.0 \mathrm{~mA})$. Although two values of shock were used $(0$ and $.5 \mathrm{~mA})$, only one value was used at a time (i.e., for any series of training and test sessions, either $.0 \mathrm{~mA}$ or $.5 \mathrm{~mA}$ was used along with the higher intensity shock). The tone signal preceded all shocks by $5 \mathrm{sec}$ and terminated with shock. During each session, high- and low-intensity shock time periods alternated on a variable time schedule ranging from $31-1,982 \mathrm{sec}$ with a mean of $10 \mathrm{~min}$.

To avoid spurious contingencies developing between shock and responding on the changeover lever, a 2.5 -sec delay was programmed beginning with shock onset. During this delay, changeover responses were ineffective in producing the correlated stimuli.

\section{Initial Training (Baseline)}

All subjects received four 6-h sessions prior to giving them the choice condition. For the first $3 \mathrm{~h}$ of each of these sessions, periods of high and low shock intensity were identified by their correlated stimuli. High and low shock periods were not identified by correlated stimuli for the last $3 \mathrm{~h}$ of each session. 
Responses on the changeover lever and time spent in changeover during this "training" and baseline condition were recorded, though these responses produced no stimulus change.

\section{Changeover to Multiple Schedule (COMULT)}

After the operant level of changeover responding on the levers had been determined, the subjects began the following sessions with the intensity of shock unidentified (i.e., mixed schedule). Depression of a changeover lever changed the mixed schedule to a multiple one where shock intensity was identified by the immediate onset of the appropriate correlated stimulus for a 1 -min period. Additional responses within this $1 \mathrm{~min}$ were nonfunctional. At the end of the 1-min period, the correlated stimulus terminated, and subjects could remain under the mixed schedule (i.e., intensity of shock unidentified) or they could reinstate the multiple schedule. Changeover responding determined only whether a correlated stimulus identifying shock intensity would be produced and did not change the program of shock delivery.

\section{Changeover to Mixed Schedule (COMIX)}

After the operant level of changeover responding on the levers had been determined, the subjects began the following sessions with the intensity of shock identified (i.e., multiple schedule). A changeover response changed the multiple schedule to a mixed one and resulted in the immediate termination of the correlated stimulus identifying the shock intensity level. All other contingencies in this condition were the same as the COMULT condition. This condition was run to determine if the stimuli identifying shock intensity acquired aversive rather than positive properties, and thus, would be turned off.

\section{Intensity Constant-Shock and Shock-Free Periods Identified}

In the event that no changeover responding occurred to any of the experimental conditions, the subjects were given both signaled and unsignaled shock training similar to the procedure described by Badia and Culbertson (1972). Appropriate baselines were determined, and subjects were then given a choice between signaled or unsignaled shock.

\section{RESULTS}

\section{Changeover to Multiple Schedule (COMULT)}

Subjects failed to respond at a sufficiently high rate on the changeover lever to change to the multiple schedule even though all subjects were given several training and testing opportunities. It made little difference whether correlated stimuli identified low$(.5 \mathrm{~mA})$ vs. high - $(1.0 \mathrm{~mA})$ intensity shock or no shock (0 $\mathrm{mA})$ vs. high (1.0 $\mathrm{mA})$ shock.

\section{Changeover to Mixed Schedule (COMIX)}

With the exception of Subject A6, none of the subjects changed from the multiple to the mixed schedule when given the option. Again, it did not matter whether the condition was low shock $(.5 \mathrm{~mA})$ vs. high shock $(1.0 \mathrm{~mA})$ or no shock vs. high shock $(1.0 \mathrm{~mA})$. However, one subject (A6) increased its rate of changeover responding sufficiently to spend about $70 \%$ of the session time under the mixed schedule. However, following an extinction condition, several subsequent attempts to replicate this performance were unsuccessful.

\section{Changeover for Signaled over Unsignaled Shock}

Since none of the subjects changed over for information about the intensity of shock, the question was asked whether these subjects would change from unsignaled to signaled shock. To answer this question, four subjects were given training under both signaled and unsignaled shock conditions. When given the option, all subjects changed from the unsignaled to the signaled condition. Figures 1, 2, and 3 show the last three sessions for all conditions for the three subjects (A7, A8, A9) that experienced all the experimental conditions. Subject A4 died before the tests were completed, but on the last 2 days of testing, this subject spent $55 \%$ and $58 \%$ of the session time in the signaled condition. As seen in the figures, the other three subjects showed a gradual increase in changeover responding. The time spent in the signaled condition, after stabilization, ranged from about 76\% (A7 and A8) to 85\% (A9). Analysis of the event records depicting changeover responding showed a high degree of control exerted by the stimulus correlated with the signaled condition. Whenever this stimulus terminated $(1 \mathrm{~min}$ after a changeover response), subjects usually reinstated it quickly and with a single changeover response.

Changeover responding returned to the baseline level in extinction, as seen in Figures 1, 2, and 3. Following extinction, changing over to signaled shock was reinstated, and once again changeover responding returned to the relatively high and stable level previously attained.

\section{DISCUSSION}

The results of this experiment suggest that information about shock intensity is not sufficiently reinforcing to result in changing to the informative condition. When given the option, none of the subjects changed from the no-information condition to the information one or vice versa.

Perhaps if other shock parameters of this experiment were varied, then information related to shock intensity would be reinforcing. For example, shock intensity changes may not have occurred often enough in order to provide for an optimal amount of information. It may be argued that since shock intensities did not change, on the average, within a 10-min period, subjects used shocks as cues for the intensity of succeeding shocks. That is, if a subject received a low-intensity shock, all of the shocks within the next $10 \mathrm{~min}$, on the average, were also of low intensity. Hence, the changeover response produced relatively little additional information. It must be pointed out that at any given point in time, the probability of a shock of a particular intensity was .50. Moreover, shock intensities did not change on a fixed 10-min schedule but sometimes changed as early as $31 \mathrm{sec}$ or as late as $33 \mathrm{~min}$. Also, the tables used to generate the shock schedules (Fleshler \& Hoffman, 1962) contained many more short intervals than long.

All subjects that were given the condition of choosing between signaled or unsignaled shock (with intensity of signaled and unsignaled shock constant) changed to the signaled condition. The latter finding indicates that while information about shock intensity is not reinforcing, information about shock (signal present) and shock-free periods (absence of the signal in the signal condition) is reinforcing. 


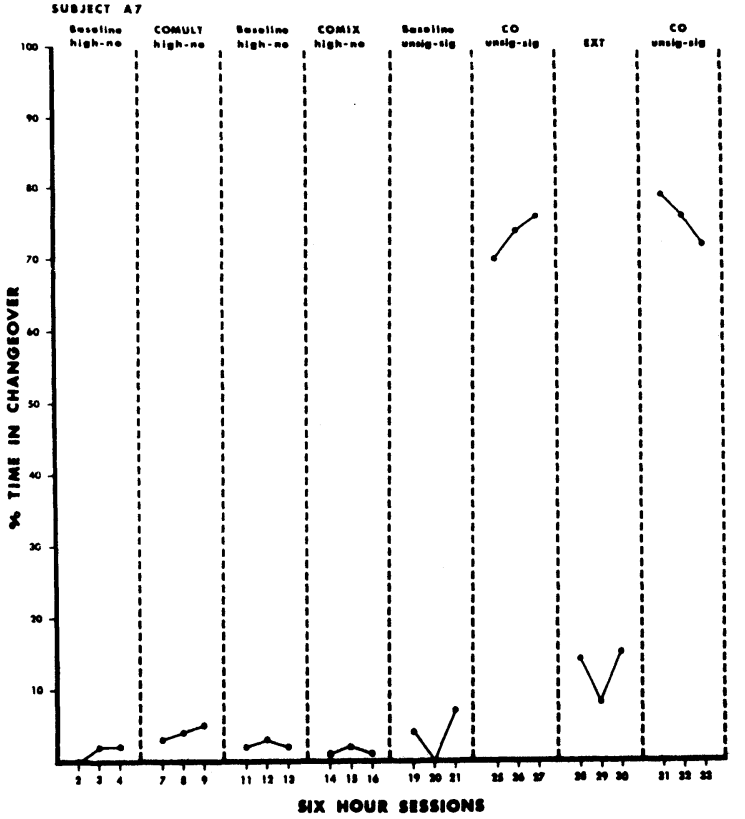

Figure 1. Performance of Subject A7 for the last three sessions of each condition of the experiment.

In general, these data support the notion that organisms prefer to be knowledgeable about certain conditions in their environment. There are three general theories that propose to account for these results. The preparatory response theory (Perkins, 1955, 1968) states that discriminative or informative stimuli enable the subject to make differential preparatory responses to optimize the value of reward or minimize the aversive effects of painful stimuli. The present findings do not support the preparatory hypothesis in that subjects did not

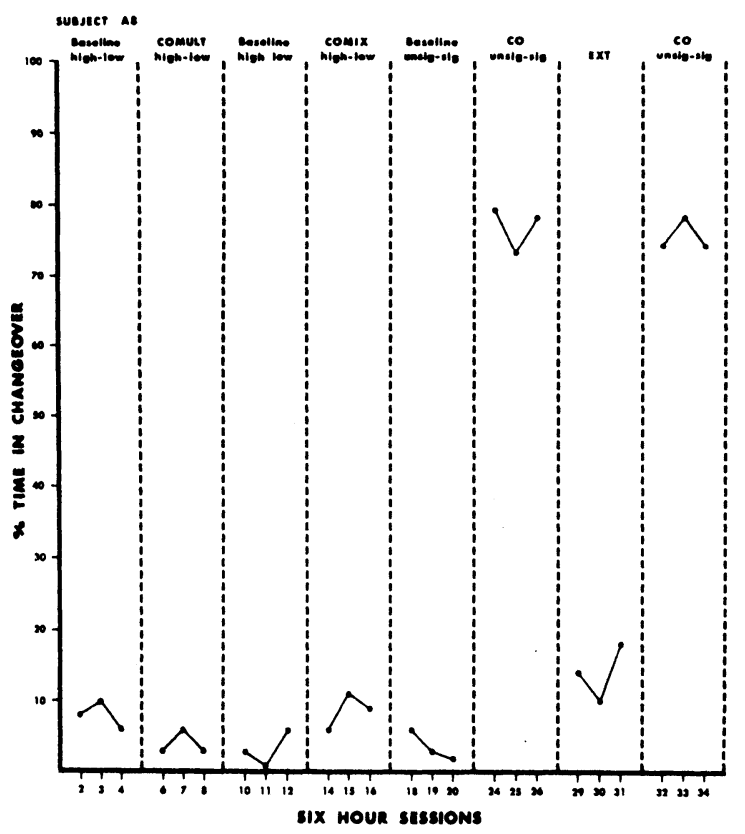

Figure 2. Performance of Subject A8 for the last three sessions of each condition of the experiment.

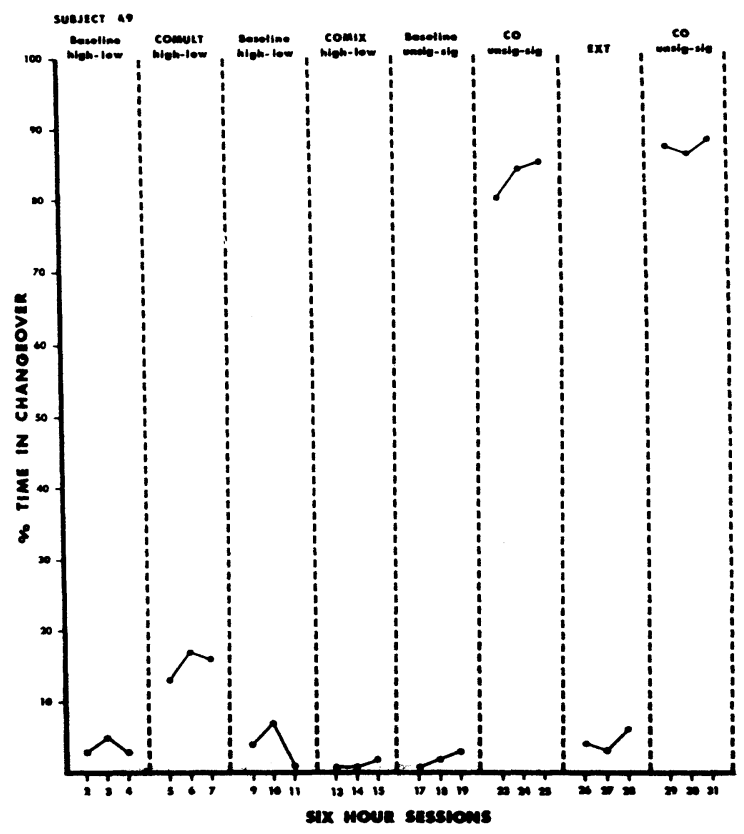

Figure 3. Performance of Subject A9 for the last three sessions of each condition of the experiment.

prefer information about the intensity of shock (either $.0 \mathrm{~mA}$ and $1.0 \mathrm{~mA}$ or $.5 \mathrm{~mA}$ and $1.0 \mathrm{~mA}$ ) to which differential preparation could have occurred.

The uncertainty reduction hypothesis (e.g., Berlyne, 1960) states that the ability of stimuli to become conditioned reinforcers depends upon the reduction of the subject's uncertainty about environmentally important events. Moreover, information is reinforcing regardless of whether it signals positive or negative events. Again, the present findings dealing with information about the intensity of shock clearly do not support an information analysis.

A third theoretical view dealing with preference for signaled aversive events is the safety analysis (Badia \& Culbertson, 1971, 1972; Seligman, Maier, \& Solomon, 1971). The safety analysis specifies that, in signaled shock situations, the presence of the signal identifies a shock period (unsafe), and its absence identifies a shock-free (safe) period. When subjects are in the signaled condition, the unsafe periods are predictable and relatively brief, lasting only as long as the signal duration (e.g., $5 \mathrm{sec})$. The safe periods also are predictable in the signaled condition, but they are considerably longer than the unsafe periods since the safe period consists of total intershock time minus the signal duration. In contrast, neither safe nor unsafe periods are identifiable in the unsignaled condition. The safety analysis implies that information about the intensity of shock is less important than information about the safe periods. The present findings tend to support the safety view.

\section{REFERENCE NOTE}

1. McLaughlin, D. L. Some necessary conditions for the acquisition of observing responses. (Doctoral dissertation, Emory University) Ann Arbor, Michigan: University Microfilms, 1969, No. 69-5239.

\section{REFERENCES}

Badia, P., \& Culbertson, S. The relative aversiveness of signalled vs. unsignalled escapable and inescapable shock. Journal of the Experimental Analysis of Behavior, 1972, 17, 463-471. 
Badia, P., Culbertson, S., \& Lewis, P. The relative aversiveness of signalled vs. unsignalled avoidance. Journal of the Experimental Analy sis of Behavior, 1971, 16, 113-121.

Berlyne, D. E. Conflict, arousal and curiosity. New York: McGraw-Hill, 1960.

Fleshler, M., \& Hoffman, H. S. A progression for generating variable-interval schedules. Journal of the Experimental Analy sis of Behavior, 1962, 5, 529-530.

Levis, D. J., \& Perkins, C. C., Jr. Acquisition of observing responses (Ro) with water reward. Psychological Reports, $1965,16,114$.

Lockard, J. S. Choice of a warning signal or no warning signal in an unavoidable shock situation. Journal. of Comparative and Physiological Psychology, 1963, 56, 526-530.
Mitchell, K. M., Perkins, N. P., \& Perkins, C. C., Jr. Conditions affecting acquisition of observing responses in the absence of differential reward. Journal of Comparative and Phy siological Psy chology, 1965, 60, 435-437.

Perkins, C. C., Jr. The stimulus conditions which follow learned responses. Psychological Review, 1955, 62, 341-348.

Perkins, C. C., Jr. An analysis of the concept of reinforcement. Psy chological Review, 1968, 75, 155-172.

Seligman, M. E. P., Maier, S. F., \& Solomon, R. L. Unpredictable and uncontrollable aversive events. In F. R. Brush (Ed.), Aversive conditioning and learning. New York: Academic Press, 1971. Pp. 347-400.

(Received for publication April 18, 197.5.) 